\title{
O Sistema Único de Saúde no Período de 2003 a 2018-9: impactos da dinâmica econômica
}

The Unified Health System from 2003 to 2018-9: impacts of economic dynamics

El Sistema Único de Salud de 2003 a 2018-9: impactos de la dinámica económica

\author{
Moacir Roberto Heimann ${ }^{1}$
}

https://orcid.org/0000-0002-3439-5851

RESUMO: Neste artigo apresentamos uma análise sobre a dinâmica econômica e os reflexos para o Sistema Único de Saúde (SUS) durante o período entre 2003 a 2018-9. A partir da análise da política econômica adotada durante o período em questão, buscaremos relacionar as políticas macroeconômicas de distribuição de renda, acesso ao crédito, investimentos públicos e política tributária com a criação de programas sociais que refletiram no SUS, destacando principalmente oS seguintes programas: Programa Bolsa Familia, Programa Fome Zero, Programa Brasil Sorridente, Programa Farmácia Popular e o fortalecimento do Programa da Saúde da Família. Outro elemento abordado no trabalho busca relacionar o período de crise de 2014 a 2018-9 e os reflexos no SUS.

PALAVRAS-CHAVE: Saúde pública no Brasil. Financiamento do SUS. Programas sociais.

ABSTRACT: This article presents an analysis on the economic growth and the reflexes for the Unified Health System (SUS) during the period between 2003 to 2018-9. From the analysis of the economic policy adopted during this period, we will seek to relate the macroeconomic policies of income distribution, access to credit, public investments and tax policy with the creation of social programs that reflected in SUS, mainly highlighting the following programs; Bolsa Familia Program, Hunger Zero Program, Brasil Sorridente Program, Popular Pharmacy Program and the strengthening of the Family Health Program.

KEYWORDS: Public health in Brazil. SUS financing. Social programs.

RESUMEN: Este artículo presenta un analisis del crecimiento enonómico y los reflejos para el Sistema Único de Salud (SUS) durante el período compreendido entre 2003 y 2018-9. A partir del analisis de la política económica adoptada durante el período en cuéstion, buscaremos relacionar las políticas macroeconómicas, distribuição de ingresos, acceso al crédito, inversiones públicas y política fiscal con la creación de programas sociales que se refeljan en el SUS, destacando principalmente los siguientes programas: Programa Bolsa Família, Programa Hambre Cero, Programa Brasil Sorridente, Programa de Farmacia Popular y el fortalecimiento del Programa de Salud Familiar.

\footnotetext{
1 Mestrando no Programa de Pós-Graduação da Universidade Estadual do Oeste do Paraná. E-mail: moarh@hotmail.com.
} 
PALABRAS-CLAVE: Salud pública en Brasil. Financiación del SUS. Programas sociales.

\section{INTRODUÇÃO}

Nosso objetivo não é tentar apresentar uma pesquisa abrangente ou superficial do histórico da formação do Sistema Único de Saúde (SUS), em vez disso, estamos tentando apresentar evidências empíricas dos efeitos econômicos sobre o modelo de saúde brasileiro, por ser um tema de profunda importância para a sociedade em geral. É importante que se entenda esta relação para que as políticas sociais e o SUS sejam amplamente divulgados e defendidos. Desta maneira, apresentamos elementos sobre o crescimento econômico e as políticas de saúde realizados entre 2003 a 2018-9. Outro objetivo é apresentar os efeitos da crise brasileira de 2014-5 e os reflexos para o SUS.

O Sistema Único de Saúde brasileiro, em vigor desde a Constituição Federal de 1988, é um complexo conjunto de serviços voltados à saúde. Todo cidadão brasileiro pode usar o SUS, pois seus serviços englobam desde o controle sanitário até os mais complexos, como cirurgias cardíacas, transplantes de órgãos e tratamentos oncológicos.

Para que os princípios de universalização, equidade e integralidade, estabelecidos na Constituição Federal (BRASIL,1988), possam se tornar realidade, é imprescindível que ocorra o crescimento econômico, o qual irá determinar a capacidade do Estado em financiar os SUS.

$\mathrm{O}$ artigo se divide em dois períodos, em um primeiro momento analisamos as principais medidas econômicas que possibilitaram o crescimento econômico entre 2003 a 2011, relacionando-as com a criação de políticas sociais e de saúde. No segundo momento a análise busca apresentar as medidas econômicas de enfrentamento a partir da crise de 2008, e os efeitos sobre as políticas sociais e sobre a saúde, principalmente a partir de 2014.

Para nosso estudo, o recorte temporal se inicia em 2003, durante o governo Lula, perpassando o governo Dilma (2011 a 2016), o governo de transição de Temer (2016-18) até o primeiro ano do atual governo (2019). Em cada período, a análise apresenta a ligação entre a agenda política econômica e os reflexos no SUS, a exemplo da criação de programas sociais e aumento na oferta de serviços e recursos financeiros e humanos no período de crescimento e a reformulação das políticas para o financiamento da saúde após a crise de 2014. 
Apresentaremos dados do Fundo Nacional da Saúde referentes ao financiamento aos níveis de atenção à saúde, básica, média e alta complexidade, com o objetivo de apresentar dados consistentes sobre a capacidade do Estado em financiar os SUS.

\section{CícLO VIRTUOSO}

Segundo Carvalho (2018), no governo Lula (2003/2011), a política macroeconômica foi sustentada por três pilares: distribuição de renda, acesso ao crédito e investimentos públicos que se somaram a um quarto pilar de fator externo; a demanda por commodities (puxadas pela demanda interna chinesa); e a alta nos preços internacionais das commodities (petróleo, minérios e produtos agrícolas).

Para Medeiros (2017), o período entre 2006 a 2010 foi marcado pela redução da dívida externa, aumento do salário mínimo acima da inflação, redução do desemprego a níveis considerados de pleno emprego, inclusão de um número significativo da população ao mercado consumidor, recuperação dos setores da economia e aumento nas exportações de commodities que permitiram acumular reservas externas. Ressalta que o aumento de renda e a ampliação do consumo dos brasileiros foi baseado na importação e, considerando somente os bens intermediários, em 2003 essas importações eram de US\$ 30,1 bilhões, chegando a US\$126,00 bilhões em 2013, representando $50 \%$ do total das importações brasileiras. Gadelha (2003, p. 528), analisa os impactos no setor industrial ligados ao setor de saúde, no que ele denomina como "complexo industrial da saúde" e aponta que a política econômica adotada a partir da década de 1990, causou a "[...] deterioração da capacidade competitiva das indústrias de saúde e como a situação constitui, de fato, um problema crítico para a política de saúde e, num âmbito mais geral, para a política nacional de desenvolvimento". [...] (GADELHA, 2003, p. 528).

O processo de desindustrialização nos setores ligados à produção de eletroeletrônicos, químicos, fármacos e produção de engenharias causou, para o setor da saúde, uma dependência comercial de produtos importados, que impactam diretamente no aumento dos custos em saúde, drenando a maior parte das receitas do SUS.

A política de distribuição de renda para os estratos da população em linha de pobreza foi, segundo Carvalho (2018), um pilar da economia pois se tornaram híbridas: a primeira foi o Programa Bolsa Família (PBF) e a segunda foi a valorização salarial. O PBF passou a beneficiar as famílias de extrema pobreza, destinando mensalmente quantias em dinheiro que variavam de acordo com a quantidade de membros da família.

Essa política foi vinculada ao SUS e à educação, pois os critérios para se manter no programa previam que as famílias seguissem as recomendações da saúde e o calendário vacinal, além de manter a frequência escolar. 
De acordo com o Ministério da Saúde, o SUS realiza serviços de saúde e o acompanhamento das famílias do Programa Bolsa Família, como a realização do pré-natal pelas gestantes, o acompanhamento do crescimento e desenvolvimento infantil e a imunização das crianças. Assim, as famílias beneficiárias do PBF atuam com mulheres em idade entre 14 e 44 anos e crianças menores de sete anos de idade, que deverão ser assistidas por uma equipe de saúde da família, por agentes comunitários de saúde ou por unidades básicas de saúde, que proverão os serviços necessários ao cumprimento das ações de responsabilidade da família (BRASIL, 2020a).

Em 2003 o número de famílias atendidas pelo PBF era de 3,6 milhões, chegando em 2010 a atender 12,8 milhões de famílias (CARVALHO, 2018). O pilar da valorização salarial pode ser explicado principalmente pelo aumento na demanda por produtos e serviços e o aumento dos empregos formais. Foi uma política keynesiana na qual "[...] a propensão a consumir e o nível do novo investimento é que determinam, conjuntamente, o nível de emprego, e é este que, certamente, determina o nível de salários reais — não o inverso" [...] (KEYNES, 1996, p. 64).

A política do PBF se tornou um investimento do Estado, e permitiu que as famílias passassem a consumir produtos e serviços que até então não podiam. Outro fator importante é a vinculação destas famílias às políticas do SUS, pois esta gerou uma demanda por mais medicamentos, vacinas, pessoal capacitado e contratação de novos serviços, assim o Estado como consumidor puxou os investimentos privados dos setores de produção de bens e serviços. Keynes (1996, p. 73) define que "[...] um aumento na demanda efetiva devido a um fortalecimento da propensão a consumir poderia encontrar-se associado a uma função de oferta agregada diferente da que corresponderia a um aumento igual da demanda devido a um maior incentivo a investir".

\begin{abstract}
O volume de emprego (e por consequência o da produção e da renda real) é fixado pelo empresário sob o motivo de procurar maximizar seus lucros presentes e futuros (sendo a previsão correspondente ao custo de uso determinada segundo a maneira como ele concebe a utilização do equipamento para que este the proporcione, no curso de sua duração, um rendimento máximo); de outro lado, o volume de emprego que the proporcionará este máximo de lucros depende da função da demanda agregada determinada pelas suas previsões de vendas que, nas diferentes hipóteses, devem resultar, respectivamente, do consumo e do investimento (KEYNES, 1996, p. 103).
\end{abstract}

Medeiros (2017) apontou que outros setores da economia foram ativados, como o setor agrícola, vide a política do PRONAF, que já existia desde 1996, porém com valores financiados e número de contratos ínfimos até os anos de 2002-3, passando ao aumento gradativo, tanto no número de contratos como no aumento dos valores, puxados pela demanda chinesa por produtos agrícolas. 
A política do Fome Zero também contribuiu para estimular a economia, mas principalmente tem um caráter de resolver as questões de igualdade do acesso aos alimentos. Com o objetivo de resolver a "fome" no Brasil, o programa Fome Zero previa garantir que as pessoas pudessem ter acesso aos alimentos em quantidade e qualidade suficientes para atender às necessidades nutricionais e a manutenção da saúde. A mesma se baseou em três eixos: a ampliação da demanda efetiva de alimentos, barateamento do preço e programas emergenciais para a população excluída do mercado (TAKAGI, 2010).

Barbosa (2013) apresenta que, em 2003, o governo elevou a alíquota COFINS de 3\% para $4 \%$ sobre as instituições financeiras e elevou a Contribuição Social sobre o Lucro Líquido (CSLL), de $12 \%$ para $32 \%$ das empresas prestadoras de serviços. Também que 0 governo promoveu em 2004 uma "pequena reforma tributária", que significou a introdução de dois regimes de arrecadação: o Programa de Integração Social (PIS), que foi ampliado e a Contribuição para Financiamento da Seguridade Social (COFINS) sobre as importações. Além disso, prorrogou por mais quatros anos a Contribuição Provisória sobre Movimentação Financeira (CPMF). Com isso, foi possível elevar a arrecadação federal em termos reais e em relação ao PIB, servindo como mais um pilar do crescimento econômico.

A base financeira que financia o SUS vem exatamente da arrecadação de impostos. Isso significa que, para o Estado ter a capacidade de aumentar a arrecadação, é necessário que as atividades dos diferentes setores da economia nacional e o consumo estejam em pleno funcionamento. Com as mudanças tributarias já citadas, foi possível ao Estado estimular/impulsionar o "círculo de acumulação de capital", transformando parte do investimento em políticas de cunho social, que no setor especifico da saúde permitiu financiar o modelo SUS e ampliar e criar novas políticas de saúde.

O crescimento econômico e as mudanças tributárias permitiram o aumento da arrecadação federal e, pela primeira vez, o SUS pôde implementar e fortalecer algumas diretrizes previstas na Constituição Federal de 1988, diferenciando o SUS ideal para o SUS possível. Em 2003, foi lançado o Serviço de Atendimento Móvel de Urgência (SAMU). No âmbito da política de atenção às urgências e emergência, o SAMU presta o serviço de nível intermediário de atenção à saúde.

Em 2004 foram criados o Programa Brasil Sorridente (que vinculou ao SUS os cuidados odontológicos) e o Programa Farmácia Popular do Brasil. O Programa Brasil Sorridente foi responsável pela criação de 500 Centros de Especialidades e Laboratórios Regionais de Próteses Dentárias, assim como do aumento de equipes de saúde bucal (que passam de pouco mais de 4.260 para 14.244), e até o ano de 2006 já havia realizado o atendimento odontológico para 70 milhões de brasileiros (MENICUCCI, 2011). 
O Programa Farmácia Popular, criado no mesmo ano (2004), firmado em conjunto com a Fundação Oswaldo Cruz, constitui outro fator importante para ativar o mercado interno de produção e consumo de medicamentos, com custos mais baixos.

As redes privadas de drogarias passaram a comercializar produtos com até $90 \%$ de desconto. Ainda na área de medicamentos, foi criada a Câmara de Regulação do Mercado de Medicamentos (CAMED), que passou a fixar normas e fiscalizar os preços dos medicamentos. Assim, foi criada a política de isenção de ICMS para produção de medicamentos de alto custo, apoio a laboratórios oficiais para que passassem a produzir medicamentos. (BRASIL, 2003).

A Constituição Federal de 1988, no que se refere sobre o financiamento do SUS, determinou que as três esferas de governo o financiem, mas foi somente em 2012, com a Lei Complementar oㅜ 141, de 13 de janeiro de 2012, que se determinou uma porcentagem anual de cada esfera que irá financiar o SUS, ficando assim definido: municípios e Distrito Federal devem aplicar anualmente, no mínimo, 15\% da arrecadação dos impostos; os estados 12\%; a União aplica o valor empenhado no exercício financeiro anterior, acrescido do percentual relativo à variação do Produto Interno Bruto $(\mathrm{PIB})$ do ano antecedente ao da lei orçamentária anual. (BRASIL, 2012).

Podemos verificar que o aumento na carga tributária permitiu elevar o valor de repasses públicos em saúde e, no Brasil, em relação ao PIB (que também registrou níveis de crescimento), a participação da União entre 2008 a 2017 passou de 1,6\% para 1,8\%. Somando a participação dos estados e munícipios, o total de gastos em ações e serviços públicos de saúde (ASPS) em ralação ao PIB passou de 3,61\%, em 2008, para 4,05\% em 2017 (Tabela 1) (OCKÉ-REIS; FERNANDES, 2018).

Tabela 01 - PIB e \% dos gastos em saúde 2008-2017 (PIB em R \$ trilhões)

$\begin{array}{llllllllr}\text { Ano: } & 2008 & 2010 & 2012 & 2013 & 2014 & 2015 & 2016 & 2017 \\ \text { PIB: } & 3.109 & 3.885 & 4.815 & 5.332 & 5.779 & 5.996 & 6.259 & 6.560 \\ \text { Saúde*: } & 3,61 & 3,57 & 3,67 & 3,66 & 3,75 & 3,89 & 3,96 & 4,05 \\ \text { *\% do PIB em relação a saúde. } & & & & & & \end{array}$

Fonte: Brasil (2018).

De acordo com os dados obtidos na publicação Aspectos Fiscais da Saúde no Brasil, o PIB de 2008 foi de $R \$ 3,1$ trilhões, evoluindo para $R \$ 6,5$ trilhões em 2017, e refletiu em maiores repasses para a saúde, mesmo que, em termos de participação na \% total do PIB, aumentou de 1,6\% para 1,8\% (BRASIL, 2018).

Em termos de valores, elaboramos a tabela 2, onde se apresenta os valores referentes ao financiamento do SUS entre 2008 a 2017, com destaque para os níveis de atenção à saúde e o quanto cada rubrica representa em porcentagem em relação ao total. 


$\begin{array}{lcccccc}\text { Tabela } 02 \text { - Gasto em saúde Brasil } 2008-2017 & \text { - União - valores em bilhões. } \\ \text { Ano } & \mathbf{2 0 0 8} & \mathbf{2 0 1 2} & \mathbf{2 0 1 4} & \mathbf{2 0 1 5} & \mathbf{2 0 1 6} & \mathbf{2 0 1 7} \\ \text { Saúde total } & 50,8 & 89,4 & 100,4 & 106,9 & 115,9 & 117,1 \\ \text { Atenção Básica (AB) } & 8,1 & 13,4 & 16,8 & 17,7 & 18,6 & 18,5 \\ \text { \% no total; AB } & 16 \% & 15 \% & 17 \% & 17 \% & 16 \% & 16 \% \\ \text { MAC } & 21,9 & 34,1 & 39,2 & 40,4 & 42,8 & 45,1 \\ \text { \% no total; MAC } & 43 \% & 38 \% & 39 \% & 38 \% & 37 \% & 39 \% \\ \text { Assistência farmacêutica } & 4,1 & 7,4 & 9,7 & 11 & 13,1 & 11,2 \\ \text { \% no total Assistência farmacêutica } & 8 \% & 8 \% & 10 \% & 10 \% & 11 \% & 10 \% \\ \text { vigilância em saúde } & 2,3 & 3,8 & 4,8 & 4,8 & 6,9 & 6,8 \\ \text { \% no total da vigilância em saúde } & 5 \% & 4 \% & 5 \% & 4 \% & 6 \% & 6 \% \\ \text { Emendas Parlamentares } & & & & 1,5 & 3,4 & 3,3 \\ \text { \% no total das emendas parlamentar } & & & & 1 \% & 3 \% & 3 \% \\ \text { Investimentos } & 1,2 & 3,4 & 4,4 & 2,9 & 2,9 & 1,7 \\ \text { \% sobre o total em investimentos } & 2 \% & 4 \% & 4 \% & 3 \% & 3 \% & 1 \% \\ \text { outros } & 13,2 & 21,4 & 25,5 & 28,6 & 28,1 & 30,4 \\ \text { \% sobre o total em outros } & 26 \% & 24 \% & 25 \% & 27 \% & 24 \% & 26 \% \\ \text { Pessoal } & 8,1 & 13,9 & 15,7 & 16,1 & 16,6 & 17,8 \\ \text { \% sobre o total com pessoal } & 16 \% & 16 \% & 16 \% & 15 \% & 14 \% & 15 \% \\ \text { Demais gastos } & 5,1 & 7,5 & 9,8 & 12,5 & 11,5 & 12,6 \\ \% \text { sobre o total em demais gastos } & 10 \% & 8 \% & 10 \% & 12 \% & 10 \% & 11 \% \\ \quad \text { Fonte: Brasil (2018). } & & & & & \end{array}$

Com os dados da publicação Aspectos Fiscais da Saúde no Brasil é possível verificar as maiores concentrações de recursos nos níveis de Média Alta Complexidade (MAC), e, somada e assistência farmacêutica, representaram, para $2017,48 \%$ do total dos gastos públicos. Mesmo a rubrica MAC mostrar aumento em relação à participação total, quando a analise apresenta a participação em porcentagem sobre o total é possível demonstrar que no nível de MAC ocorreu uma retração de 4\% em relação a 2008. Chama a atenção o valor referente à rubrica "outros", passando de 13,2\% em 2008 para 30,4\% em 2017. A rubrica "outros", de acordo com o Ministério da Saúde, compreende a complementação de recursos destinados ao combate de epidemias, tanto no âmbito regional como federal, é o caso da epidemia da dengue e a crise do H1N2 no Brasil. Vejamos na tabela 2 a relação entre o total em recursos e a porcentagem em cada rubrica.

Chama atenção a rubrica "investimentos". De 2008 a 2014, os investimentos na área de saúde apresentam crescimento, tanto em termos gerais quanto na participação na porcentagem sobre o total, porém, a partir de 2015, registra queda, chegando a $1 \%$ sobre 0 total investido em saúde em 2017. As quedas registradas na tabela 2 são reflexos da crise econômica que afetou o Brasil a partir de 2014-5. Veremos adiante no texto os elementos principais da crise e os efeitos para o SUS.

O IPEA analisou a proporção dos gastos em Ações e Serviços Públicos de Saúde (ASPS) e a relação per capita, que consiste em verificar o total empenhado por estados, munícipios e União em relação ao total da população, para se chegar a um valor per capita nacional. A média per capita nacional para 2017 foi de $\mathrm{R} \$ 1$ 1.068. Aponta para variações estaduais e regionais. De acordo com esse levantamento, a média per capita mais baixa se 
registrou no estado do Pará com $R \$ 707,67$, e a média per capita mais elevada foi registrada no estado de Roraima com $\mathrm{R} \$ 1.830$ (OCKÉ-REIS; FERNANDES).

Ainda de acordo com o IPEA, apenas Mato Grosso do Sul (R\$1.512), Tocantins (R\$ $1.500)$, e Acre ( $R \$ 1.309)$ se somam à Roraima entre os estados que tiveram valores per capita acima da média nacional. O estado de Minas Gerais, que apresenta alta concentração populacional, teve resultado menor em relação à média geral nacional, com o valor de $\mathrm{R} \$ 1.023$, média per capita habitante. (OCKÉ-REIS; FERNANDES).

Além do estado do Pará, outros estados registraram média per capita bem abaixo da média per capita nacional, entre eles se destacam Maranhão ( $R \$ 778)$, Bahia $(R \$ 784)$, Alagoas ( $R$ \$ 905), Ceará ( $R$ \$ 905), Amazonas ( $R$ \$ 922), Pernambuco ( $R$ \$ 913), Goiás ( $R$ \$ 916), Paraíba ( $R \$$ 936), Sergipe ( $R \$ 944)$ e Rio Grande do Norte (R\$ 956) (OCKÉ-REIS; FERNANDES, 2018).

Para verificar a distribuição dos recursos por grandes regiões brasileiras, utilizamos os dados do Ministério da Saúde, disponíveis no Sistema de Informação sobre Orçamentos Públicos em Saúde (SIOPS) Indicadores Municipais, sobre os repasses de recursos financeiros por região e, em seguida, utilizamos os dados do Ministério da Saúde sobre a estimativa populacional. (BRASIL, 2020b; DATASUS, 2019).

Em 2017, a região Sudeste concentrou o total de 39\% dos recursos e representou $42 \%$ da população brasileira. A região Centro Oeste foi a que apresentou as menores taxas, $7 \%$ no total dos repasses e $8 \%$ no total do índice populacional. Veremos a seguir esse comportamento para 2018.

Compilamos e analisamos os dados e elaboramos dois gráficos para demonstrar a espacialização dos repasses em saúde por grandes regiões. A figura 01 é referente aos repasses para a saúde em relação à população para o ano de 2017.

Figura 01 - Distribuição por região dos repasses nacionais para saúde e do total de habitantes - Brasil 2017

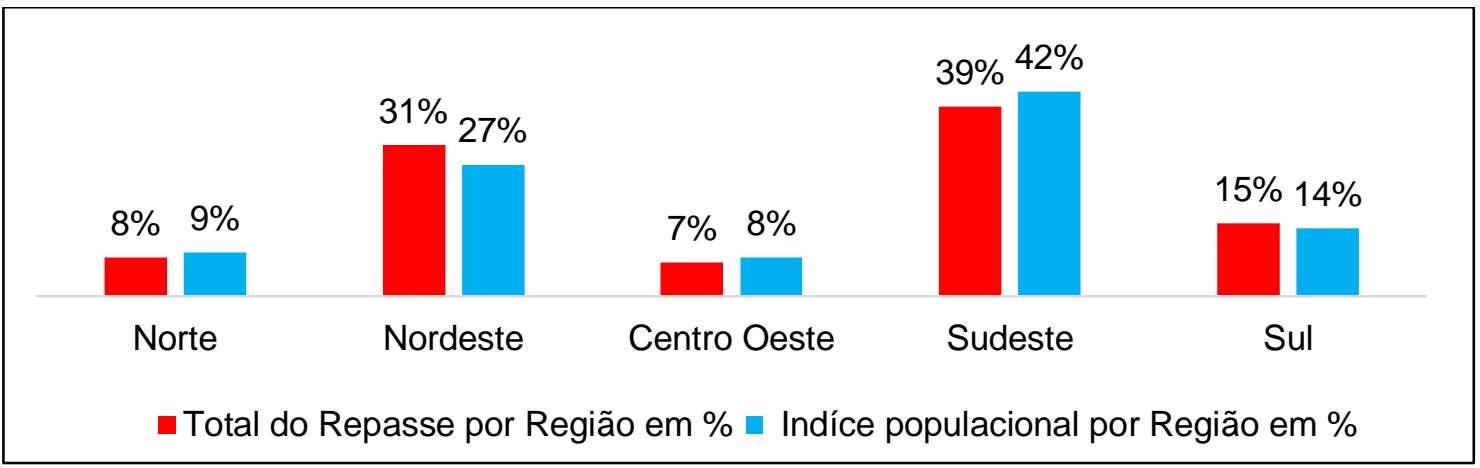

Fonte: Agência Nacional de Saúde Suplementar (2019) e Brasil (2020a).

$\mathrm{Na}$ figura 2 apresentamos esses dados referentes a 2018. Com base nos dados, existe uma diferença na proporção de distribuição de recursos para a saúde em relação à 
população. Para o ano de 2018, podemos observar que ocorreu aumento nas transferências dos recursos para a região Sudeste, passando de 39\% em 2017 para 48\% em 2018, com diminuição para as regiões Norte (de 8\% em 2017 para 6\% em 2018) e Nordeste (de 31\% em 2017 para $23 \%$ em 2018).

Figura 02 - Distribuição por região dos repasses nacionais para saúde e do total de habitantes - Brasil 2018

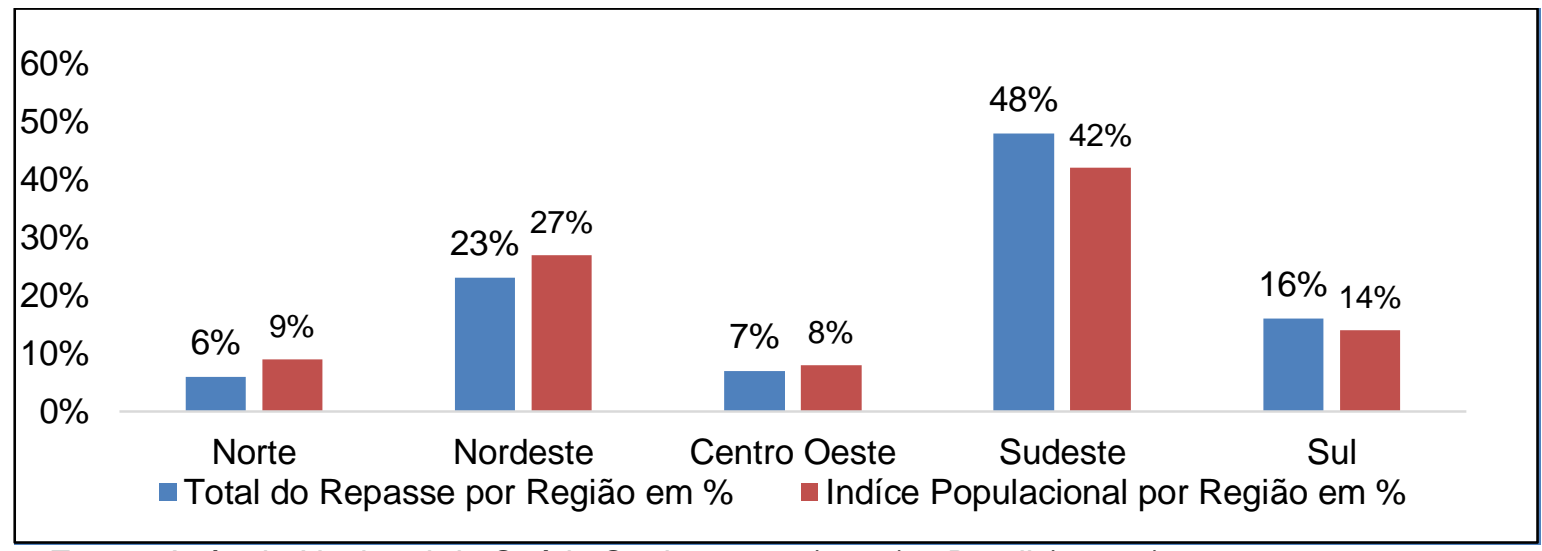

Fonte: Agência Nacional de Saúde Suplementar (2019) e Brasil (2020a).

Observamos no gráfico as proporções da distribuição dos recursos da saúde por região e a representação populacional que cada região representa em porcentagem sobro o total populacional.

A região Centro Oeste registrou os mesmos índices de 2017 e a região Sul teve aumento de $1 \%$ no total de repasses para a saúde. Esse panorama pode significar mais desigualdades regionais e afetar as prestações de serviços de saúde às populações destas regiões.

Ocorreu saldo positivo no que se refere aos recursos humanos. Os dados do Ministério da Saúde (DATASUS, 2020) mostram o aumento no número de profissionais da saúde e afins. Elaboramos uma tabela para mostrar o aumento no número de profissionais da saúde, com destaque para a área de enfermagem e medicina, referente ao período de 2007 a 2018.

A tabela 3, com os dados referentes aos recursos humanos para a área de saúde, nos permite verificar os reflexos positivos para o setor de saúde como um todo, em termos gerais, contemplando todas as categorias profissionais ligadas à saúde, as quais registraram uma média anual de $8 \%$ de crescimento. Levando em conta todo o período, o crescimento foi de $67 \%$ em relação a 2007.

Considerando todo o período entre 2007 a 2018, o aumento total foi de $95 \%$. O maior destaque em crescimento foi na área de Enfermagem, que neste período cresceu $228 \%$, passando de pouco mais de 60 mil enfermeiros em 2007 para 199 mil enfermeiros em 2018. No que se refere ao número de médicos, em 2018, a proporção em relação à população 
teve média nacional de 1,93 médicos por 1000 habitantes ou 517 habitantes para cada médico. Mas é uma questão que necessita de análise mais profunda, para verificar a realidade da questão da cobertura médica nacional e local.

$\begin{array}{lcccc}\text { Tabela 3 - Recursos humanos/Brasil } & -2007 / 2018 & & \\ \text { Período } & \mathbf{2 0 0 7} & \mathbf{2 0 1 0} & \mathbf{2 0 1 5} & \mathbf{2 0 1 8} \\ \text { Enfermagem } & 60.844 & 91.645 & 162.149 & 199.658 \\ \text { Medicina } & 246.284 & 295.488 & 352.110 & 396.313 \\ \text { Total/Afins } & 1.482 .523 & 1.845 .646 & 2.470 .364 & 2.891 .949 \\ \text { * Afins compreende a totalidade dos profissionais vinculados a área de } & \text { saúde; } & \text { Biomedicina, } \\ \text { Farmácia, Fisioterapia, Fonoaudiologia, Nutrição, Psicologia e Odontologia. } & & \\ \text { Fonte: Datasus (2020). }\end{array}$

Com a população do censo de 2010 e a estimativa populacional para 2018 (BRASIL, 2020i), é possível observar que ocorreu crescimento real nos recursos humanos para a saúde. Em 2010, existiam 9,6 profissionais da saúde para cada 1000 habitantes e, em 2018, eram 13,8 profissionais da saúde para cada 1000 habitantes (tabela 4). Enquanto a população teve um crescimento de $10 \%$, os profissionais na saúde tiveram um crescimento de $57 \%$, considerando o período como um todo.

$\begin{array}{lccc}\text { Tabela } & 4 & - \text { Recursos humanos da saúde por } 1000 \text { hab. }-2010 \text { e } 2018 \\ \text { Ano } & \text { População } & \text { Rec. Humanos } & \text { Rec. Humanos/1000hab. } \\ \mathbf{2 0 1 0} & 190.732 .694 & 1.845 .646 & 9,6 \\ \mathbf{2 0 1 8} & 209.186 .802 & 2.891 .949 & 13,8\end{array}$

Fonte: Datasus (2020).

Nos dados disponíveis na base de dados do SUS (DATASUS, 2020), com recorte temporal a partir de 2008, é possível observar o aumento na oferta de médicos. Utilizamos os dados referentes aos anos de 2008, 2013 e 2016, e desta maneira é possível comprovar um crescimento maior no número de médicos no Brasil e por grandes regiões em relação a população brasileira total. Vejamos a tabela 5 .

Tabela 5 - Número de médicos por regiões em relação à população total referente aos anos de 2008, 2013 e 2016

$\begin{array}{lcccc}\text { Regiões } & \mathbf{2 0 0 8} & \mathbf{2 0 1 3} & \mathbf{2 0 1 6} & \text { aumento\% } \\ \text { Norte } & 10.631 & 14.417 & 17.456 & 64 \% \\ \text { Nordeste } & 46.037 & 59.629 & 67.595 & 47 \% \\ \text { Sudeste } & 135.020 & 175.537 & 195.670 & 45 \% \\ \text { Sul } & 38.425 & 50.076 & 58.586 & 52 \% \\ \text { Centro O. } & 18.350 & 24.613 & 28.363 & 55 \% \\ \text { Total Méd. } & 248.463 & 324.272 & 367.670 & 48 \% \\ \text { Pop. Total } & 189.612 .814 & 201.032 .714 & 206.081 .432 & 9 \% \\ \text { med./1000hab. } & 1,31 & 1,61 & 1,78 & 36 \% \\ \text { hab./med. } & 763 & 620 & 561 & \end{array}$


Na tabela 6 apresentaremos os dados da população total por regiões brasileiras e o número de médicos, bem como a concentração por região. Levando em conta a população regional, a primeira conclusão é a concentração de médicos na região Sudeste, com 41,84 $\%$ da população brasileira, abrigando $53 \%$ do total de médicos. A proporção de médicos por 1000 habitantes é de 2,40 (ou 415 habitantes para cada médico disponível e 0,72 \% acima da média nacional).

Tabela 6 - Distribuição populacional por regiões, distribuição de médicos por região e

Regiões

Norte

Nordeste

Sudeste

Sul

Centro-Oeste

Total:

Fonte: Datasus (2020) médicos por 1000 hab. - Brasil 2018

A segunda conclusão é a de que as regiões Norte e Nordeste têm os menores índices de cobertura médica. A região Norte concentra $8,68 \%$ da população e $5 \%$ de médicos, ficando abaixo da média nacional, com 1,01 m/1000h (ou 985 habitantes para cada médico disponível).

A região Nordeste representa 27,52 \% da população brasileira e, segundo os dados do MS, compilados na tabela acima, abriga $18 \%$ do total de médicos para 2018 , o que significa 1,25 médicos por 1000 habitantes (ou 797 habitantes por médico), abaixo da média nacional $(1,93)$.

A região Sul representou, para 2018, 14,27 \% da população brasileira e o percentual de médicos em relação ao total nacional foi de $16 \%$. O número de médicos por 1000 habitantes ficou em 2,15, acima da média nacional, (ou 464 habitantes para cada médico).

A região Centro Oeste representou 7,69 \% da população em 2018 e o percentual de médicos foi de $8 \%$, o que deu uma proporção de 1,93 médicos por habitante (517 habitantes por médico).

Como podemos observar, levando em conta as grandes regiões brasileiras, somente a região Norte apresentou a relação médicos por habitantes inferior à média nacional e todas as regiões apresentaram índices superiores ao recomendado pela OMS.

Para verificar a proporção mais próxima da realidade, utilizaremos o critério de separar a população entre usuários exclusivos do SUS dos usuários que possuem planos de saúde com exclusividade em atendimento médico. Essa metodologia nos permitirá evidenciar a dinâmica real da realidade do atendimento médico brasileiro. 
Os dados da Agência Nacional de Saúde Suplementar (2019), apontam que em 2018 no Brasil os beneficiários de planos privados de saúde representaram $23 \%$ da população e é imprescindível a análise sobre essa informação.

Para analisar a relação entre a disponibilidade de médicos entre o setor da saúde pública e da saúde privada, usamos como metodologia a quantificação do número total de usuários de planos de saúde com cobertura médica disponibilizado pela Agência Nacional de Saúde Suplementar para 2018 e utilizamos os dados do Ministério da Saúde (DATASUS, 2020) referente a quantidade de médicos no Brasil em 2018. Separamos os médicos que atendem pelo SUS dos médicos exclusivos para atendimento privado. Na tabela 7 , a seguir, apresentamos o resultado para o Brasil, utilizando a metodologia descrita acima.

Tabela 7 - Proporção entre a cobertura de médicos no setor público e privado por 1000 hab. - Brasil 2018.

$\begin{array}{lcccc}\text { Brasil } & \text { População } & \text { No Médicos } & \text { Médicos/1000hab. } & \text { Habitante/médico } \\ \text { Público/SUS } & 162.036 .940 & 290.155 & 1,79 & 558 \\ \text { Privado } & 47.149 .862 & 106.158 & 2,25 & 444 \\ \text { Total } & 209.186 .802 & 396.313 & 1,89 & 527\end{array}$

Fonte: DATASUS (2020).

Como exposto acima, usando a metodologia de separação entre a população usuária de planos de saúde da população dependente dos médicos do SUS, em relação aos médicos que atendem exclusivamente o setor privado, muda-se a média nacional, ficando oito pontos abaixo da média, considerando a totalidade, ou seja, de 1,89 para 1,79 médicos/1000hab. Assim passa de 527 habitante por médico para 558 e aumenta a proporção em $16 \%$ na média nacional para o setor privado, chegando a 2,25 médicos/1000hab., ou 444 hab. por médico.

Em 2013, no governo de Dilma, foi criado a política do Programa Mais Médicos (PMM) com o objetivo de suprir a falta desses profissionais nos municípios do interior e nas periferias das grandes cidades (MS, 2013). O acordo foi realizado entre Brasil e Cuba para a vinda de médicos para atuar na atenção básica de saúde, alocados nas unidades básicas de saúde.

A política do PMM permitiu a ampliação dos atendimentos na atenção básica, principalmente nas regiões do interior e entre 2013 e 2015 foram atendidos 4 mil municípios brasileiros, sendo que, destes, 700 municípios estavam localizados em áreas remotas e passaram a ter, pela primeira vez, médico residindo na localidade para atendimento na atenção básica (BRASIL, 2015). 
$\mathrm{Na}$ tabela a seguir (tabela 8) apresentamos os dados referentes ao número de municípios que aderiram ao PMM, bem como os números referentes à cobertura populacional em relação aos municípios que não aderiram ao PMM.

Tabela 8 - Número de municípios aderidos ao PMM e população coberta, 2017 Municípios $\%$

População total

População coberta

$\%$

Aderidos

Aderidos

$3.995 \quad 71,7 \%$

187.518.751

128.894.241

$62,1 \%$

Não aderidos $1.575 \quad 28,3 \%$

Total $\quad 5.570 \quad 100,0 \%$

20.139.310

78.763.820

$37,9 \%$

Fonte: Viacava et al. (2020).

No primeiro ano do Mais Médicos a cobertura de atenção básica de saúde aumentou de $10,8 \%$ para 24,6\%. Em relação à toda a Estratégia de Saúde da Família (incluindo Mais Médicos), a cobertura municipal chegou a 71,7\% e alcançou 62,1\% da população em 2017. A seguir veremos a distribuição geográfica do PMM pelo território brasileiro (figura 3). Podemos observar como as regiões Norte, Nordeste e a linha de fronteira foram beneficiadas com o programa.

Figura 3 - Localização geográfica dos municípios mais vulneráveis que aderiram ao PMM (2013)

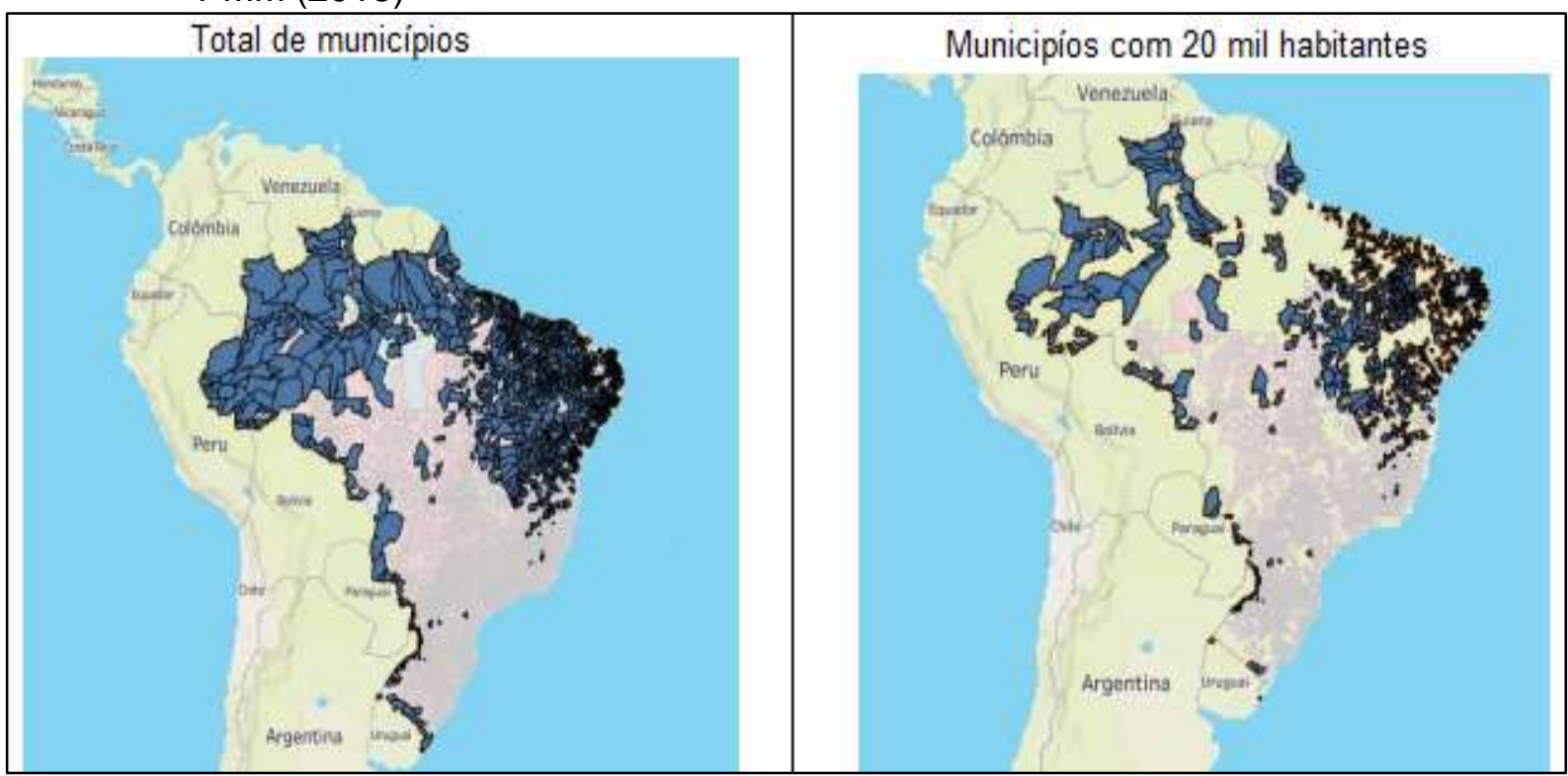

Fonte: Viacava et al. (2020).

Mesmo apresentando resultados positivos, o Programa Mais Médicos com profissionais cubanos foi interrompido em 2019. O governo eleito se opunha, desde o início do programa, ainda em 2013, quando o ainda deputado Jair Bolsonaro protocolou uma ação no Supremo Tribunal Federal (STF) para suspender o programa. Durante a campanha e após eleito, o atual presidente criou várias narrativas para justificar o fim da parceria com 
Cuba e, após acusações sem fundamentos, utilizou o Revalida como meio político de justificar o fim do acordo (MAIS MÉDICOS..., 2018).

\section{A CRISE ECONÔMICA E OS REFLEXOS NO SUS - 2015 A 2019}

Para entender as atuais políticas brasileiras como a Emenda à Constituição n 95 de 2016 (EC do Teto dos Gastos Públicos), que limitam os gastos da União em saúde e educação por 20 anos, precisamos buscar entender os elementos históricos que contribuíram para que tais medidas fossem propostas. (BRASIL, 2016).

A crise imobiliária dos Estados Unidos (2008-9) afetou as economias dos países mundo afora. De acordo com Giovanella e Stegmüller (2014), os efeitos da crise econômica de 2008 refletiram nas políticas de saúde dos países europeus e os autores demonstram que na Alemanha, Inglaterra e Espanha os governos adotaram reformas em seus sistemas de saúde. Em 2012 a Espanha formulou uma lei nacional, o "Real Decreto Lei no 16/2012 42", que significou o corte de sete de bilhões de euros do Sistema Nacional de Saúde daquele país. Também incluíram na lei espanhola mudanças "[...] na cobertura populacional, excluindo imigrantes ilegais, alterou a carteira comum de serviços, ampliou copagamentos, e incorporou mudanças na regulação da assistência farmacêutica" [...] (GIOVANELLA; STEGMÜLLER, 2014, p. 10).

A Inglaterra reformulou sua política em 2012, com o Health and Social Care Act e o National Health Service (NHS), o que significou cortes no valor de 20 bilhões de libras no prazo de cinco anos, além de permitir a privatização de serviços de saúde. Na Alemanha, os efeitos da crise foram utilizados para aumentar as contribuições para o Fundo de Saúde do Gesetzliche Krankenversicherung (GKV), e a contribuição em 2010 passou a ser de 15,5\%, sendo $7,3 \%$ dos empregadores e $8,2 \%$ sobre os salários dos trabalhadores (GIOVANELLA; STEGMÜLLER, 2014).

No Brasil, segundo Carvalho (2018), um conjunto de fatores e medidas políticas foram responsáveis por reduzir o crescimento econômico que vinha se desenvolvendo desde 2003. Entre os fatores, a autora destaca o fator externo, a crise de 2008 , que afetou os preços internacionais das commodities, reduzindo os valores sobre estas. Internamente, as políticas econômicas adotadas pela Presidente Dilma Rousseff não foram suficientes ou foram ineficazes para que a economia voltasse a crescer. Internamente, o consumo, um dos pilares do crescimento econômico, foi baseado na dependência da importação de produtos industrializados. Vejamos Carvalho (2018, p. 43):

A fragilidade da indústria tornou-se mais clara após a crise de 2008-9, quando começou a haver um descolamento cada vez maior entre comércio varejista, que volta a crescer ao ritmo do pré-crise, e produção industrial, 
que, por sua vez, cresceu muito mais lentamente. Se o comércio cresce e a indústria não, é porque os produtos comprados estão sendo produzidos em outro lugar. De fato, o total de importações do país cresceu $103,4 \%$ no acumulado entre o fim de 2005 e o fim de 2010, em termos reais.

Diante desde quadro, destaca Carvalho (2018, p. 43) "[...] aquela dinâmica de crescimento do consumo estava, em boa parte, vazando para fora do país" [...]. Diante destes fatos, as medidas adotadas para superar a crise que vinham criando maior envergadura não foram eficazes, pelo contrário, aprofundaram a crise e levaram o país a uma crise política que culminou com o impedimento da presidente Dilma Rousseff. Durante o governo Dilma foi implementada como agenda central a política de desonerações tributarias como medida para impulsionar a indústria e aumentar o consumo.

Ainda segundo Carvalho (2018), o Plano Brasil Maior (2011) foi responsável pela redução do IPI sobre máquinas e equipamentos, no setor de produção de materiais para construção e no setor automobilístico e ainda criou um sistema de créditos tributários para o setor exportador e a desoneração da folha de pagamentos.

A política de desonerações ainda foi estendida sobre o consumo das famílias, com a redução das alíquotas do PIS/Pasep, COFINS e do IPI sobre produtos alimentícios e de higiene. Carvalho (2018) demonstra que a desoneração da folha de pagamentos na forma de redução da Contribuição Previdenciária Patronal passou de $20 \%$ sobre a folha de salários para $1 \%$ e $2 \%$ sobre o faturamento da pessoa jurídica. Essa política, que em um primeiro momento foi setorial, passou para 54 setores da economia. De acordo com os dados de Carvalho (2018), de 2011 a 2018 a soma das desonerações somou mais de 458 bilhões. Diferentemente do que ocorreu com a política tributária do início do governo Lula, que permitiu ao Estado arrecadar mais impostos e transferi-los na forma de programas e investimentos, o que aconteceu a partir de 2011 foi uma forte redução na arrecadação de tributos pelo governo federal. O custo anual das renuncias tributarias passou de 140 bilhões em 2010 para 250 bilhões em 2014.

Para Teixeira e Paim (2018, p. 14-15) a crise trouxe mudanças profundas para a saúde, das quais os autores listam como consolidadas nove das 13 propostas apresentadas pelo governo, e são elas:

1) Abertura da saúde ao capital estrangeiro; 2) PL das Terceirizações; 3) Prorrogação da Desvinculação das Receitas da União (DRU), acrescida da Desvinculação das Receitas dos Estados (DRE) e da Desvinculação das Receitas dos Municípios (DRM); 5) Proposta de Emenda Constitucional (PEC 241) da Câmara dos Deputados e PEC 55 do Senado (Novo Regime Fiscal); 6) Rejeição da Emenda Popular Saúde + 10; 7) Orçamento impositivo; 8) Reconhecimento da constitucionalidade das OS; 9) Saúde, educação e ciência e tecnologia como moeda de troca político-partidária. 
Esta forma de "fazer política" se refletiu através das emendas parlamentares destinadas à saúde. Vimos na tabela 2 que desde 2015 os repasses via emenda parlamentar representavam 3,3\% sobre o total investido em saúde.

Modelos de saúde do porte do SUS só são possíveis através do crescimento econômico e, principalmente, com políticas tributárias que permitam aumentar a arrecadação federal. As consequências da crise vivenciada no Brasil a partir de 2014-5 tiveram impactos para a saúde como um todo. Para dar garantia jurídica à redução nos investimentos na área de saúde pública foi criada a EC № 95.

A Emenda Constitucional 95 (EC-95) que congela os gastos públicos na área social para os próximos 20 anos, foi caracterizada de 'austericídio', por Teixeira e Paim (2018), porque o aumento da população e o seu envelhecimento demandará maiores investimentos em saúde, ao tempo que a EC 95 fixa os recursos pela inflação, significando na prática a redução do gasto per capita com saúde.

A matéria publicada no Brasil de Fato, assinada pela jornalista Marina Duarte de Souza, na qual traz informações sobre os efeitos da EC-95 para a saúde, demostra que está ocorrendo redução no orçamento para a saúde, com a diminuição de $R \$ 20$ bilhões em 2019. De acordo com Souza (2020), em 2017 os investimentos em saúde representavam 15,77\% da arrecadação da União e em 2019 essa proporção passou a ser de 13,54\%. Isso significa que se em 2019 o investimento destinado a saúde estivesse na casa dos 15,77\%, o orçamento para a saúde alcançaria em valores equivalentes a $R \$ 142,8$ bilhões, valor superior aos $R \$ 122,6$ bilhões aplicados, o que deu uma diferença de $R \$ 20,19$ bilhões a menos de recursos para o SUS em 2019.

Esse novo momento vivenciado na economia nacional, no qual o governo adotou como projeto a chamada austeridade de ajuste da economia que, condicionada na redução dos gastos públicos e do papel do Estado como indutor do crescimento econômico e promotor do bem-estar social, se mostram seletivas e excludentes e tem na EC 95 a garantia jurídica de impor redução dos investimentos nas principais aéreas sociais (saúde e educação) por 20 anos. (BRASIL, 2016). Devemos considerar um cenário epidemiológico e o envelhecimento da população que, ao contrário do que está previsto pela EC 95, demandará aumento do valor investido em saúde, diante da necessidade de atendimento da população que depende exclusivamente do SUS e do aumento dos custos para manter a rede de assistência, principalmente na média e alta complexidade que está atrelada à dependência de importações (BRASIL, 2016). 


\section{CONSIDERAÇÕES FINAIS}

Ao longo do texto apresentamos dados referentes ao crescimento econômico nacional entre 2003 a 2011 e os reflexos positivos para a criação de políticas públicas de saúde, bem como demonstramos que a partir da crise imobiliária americana de 2008 a economia brasileira passou a sentir os reflexos da crise e, na busca da recuperação, o governo Dilma passou a adotar como agenda central as desonerações tributárias.

Vimos que o crescimento econômico refletiu positivamente para o SUS, possibilitando a criação e a ampliação dos programas de saúde. Demonstramos que além do aspecto financeiro, os recursos humanos também tiveram aumentos, principalmente na área de enfermagem. Quanto à área médica, vimos que a relação entre o número de médicos por 1000 habitantes também teve saldo positivo. Enquanto que na década de 1990 a média era de 1,18 méd. /1000hab, ou seja, 1.180 habitantes por um médico, em 2018 essa proporção superou números indicados pela OMS de um médico por cada 1000 habitantes. Em média geral, os dados demonstram que a relação entre o número de habitantes e médicos foi de 1,89 médicos por 1000 habitantes, ou seja, 527 habitantes por um médico. Esta relação não se apresenta homogênea, variando entre as regiões e concentrando o maior número de médicos na região Sudeste e menor número na região Norte.

A crise de 2014-15 afetou todos os setores da economia e, como reflexo para o SUS, trouxe a mudança na forma de financiar o modelo de saúde, com a EC nํ95. Apresentamos nosso argumento de que a EC no 95 poderá impactar negativamente o SUS, pois, entre outras mudanças, congela os aumentos em saúde por 20 anos.

Nosso principal objetivo, neste texto, foi mostrar que só pode existir um modelo de saúde como o SUS com políticas de Estado voltadas ao desenvolvimento econômico vinculadas à criação de programas sociais que permitam colocar em prática o estabelecido na CF de 1988.

\section{REFERÊNCIAS}

AGÊNCIA NACIONAL DE SAÚDE SUPLEMENTAR - ANS. Setor de planos de saúde encerra o ano estável. Rio de Janeiro, RJ: ANS, 2019. Disponível em: http://www.ans.gov.br/aans/noticias-ans/numeros-do-setor/4833-setor-de-planos-de-saudeencerra-o-ano-com-47-3-milhoes-debeneficiarios\#: :text=O\%20setor\%20encerrou\%20o\%20ano,nos\%20dois\%20tipos\%20de\%2 0segmenta\%C3\%A7\%C3\%A3o. Acesso em: 20 fev. 2020.

BARBOSA, Nelson. Dez anos de política econômica. In: SADER, E. Lula e Dilma: dez anos de governos pós-neoliberais no Brasil. São Paulo: Boitempo: Flacso, 2013. p. 69-102.

BRASIL. [Constituição (1988)]. Constituição da República Federativa do Brasil de 1988. Brasília, DF: Presidência da República, 1988. Disponível em:

http://www.planalto.gov.br/ccivil_03/constituicao/constituicaocompilado.htm 
BRASIL. Legislação Informatizada - Emenda Constitucional № 95, de 2016 - publicação original. Altera o Ato das Disposições Constitucionais Transitórias, para instituir o Novo Regime Fiscal, e dá outras providências. Brasília: Câmara dos Deputados, 2016. Disponível em: https://www2.camara.leg.br/legin/fed/emecon/2016/emendaconstitucional-95-15dezembro-2016-784029-publicacaooriginal-151558-pl.html. Acesso em: 20 abr. 2020.

BRASIL. Lei complementar № 141, de 13 de janeiro de 2012. Regulamenta o § 3o do art. 198 da Constituição Federal para dispor sobre os valores mínimos a serem aplicados anualmente pela União, Estados, Distrito Federal e Municípios em ações e serviços públicos de saúde; [...].Brasília, DF: Presidência da República, 2012. Disponível em: http://www.planalto.gov.br/ccivil_03/leis/lcp/lcp141.htm. Acesso em: 20 abr. 2020.

BRASIL. Lei no 10742, de 06 de outubro de 2003. Define normas de regulação para o setor farmacêutico, cria a Câmara de Regulação do Mercado de Medicamentos - CMED e altera a Lei no 6.360, de 23 de setembro de 1976, e dá outras providências. Brasília, DF: Presidência da República, 2003. Disponível em: http://www.planalto.gov.br/Ccivil_03/leis/2003/L10.742.htm. Acesso em: 15 maio 2020.

BRASIL. Ministério da Fazenda. Tesouro Nacional. Aspectos fiscais da saúde no Brasil. Brasília: Secretaria do Tesouro Nacional, 2018. Boletim, 31 out. 2018. Disponível em: http://www.tesouro.fazenda.gov.br/documents/10180/318974/AspectosFiscaisSa\%C3\%BAd e2018/a7203af9-2830-4ecb-bbb9-4b04c45287b4. Acesso em: 15 fev. 2020.

BRASIL. Ministério da Saúde. Secretaria de Atenção Primária à Saúde. Programa Bolsa Família. Brasília, DF: Ministério da Saúde, 2020a. Disponível em: https://aps.saude.gov.br/ape/bfa. Acesso em: 14 fev. 2020.

BRASIL. Ministério da Saúde. Secretaria de Gestão do Trabalho e da Educação na Saúde. Programa Mais Médicos: dois anos: mais saúde para os brasileiros. Brasília, DF: Ministério da Saúde, 2015. Disponível em:

http://bvsms.saude.gov.br/bvs/publicacoes/programa_mais_medicos_dois_anos.pdf 2015. Acesso em: 11 maio 2020.

BRASIL. Ministério da Saúde. Sistema de Informações Sobre Orçamentos Públicos em Saúde -SIOPS. Cartilha de orientação. Brasília, DF, 2020b. Disponível em: http://siops.datasus.gov.br/Documentacao/cartilha_2020.pdf. Acesso em: 19 fev. 2020. CARVALHO, Laura. Valsa brasileira: do boom ao caos econômico. São Paulo: Todavia, 2018.

DATASUS - Departamento de Informática do SUS. Cadastro Nacional de Estabelecimentos de Saúde. Recursos Humanos - profissionais - indivíduos- segundo CBO de 2002 Brasil. Brasília, DF: Ministério da Saúde, 2020. Disponível em: http://tabnet.datasus.gov.br/cgi/deftohtm.exe?cnes/cnv/prid02br.def. Acesso em: 19 fev. 2020.

DATASUS - Departamento de Informática do SUS. População residente - estimativas para o TCU - Brasil. Brasília, DF: Ministério da Saúde, 2019. Disponível em: http://tabnet.datasus.gov.br/cgi/tabcgi.exe?ibge/cnv/poptbr.def. Acesso em: 19 fev. 2020.

GADELHA, Carlos Augusto Grabois. O complexo industrial da saúde e a necessidade de um enfoque dinâmico na economia da saúde. Ciência e Saúde Coletiva, Rio de Janeiro, RJ, v. 8, n. 2, p. 521-535, 2003.

GIOVANELLA Ligia; STEGMÜLLER, Klaus. Crise financeira europeia e sistemas de saúde: universalidade ameaçada? Tendências das reformas de saúde na Alemanha, Reino Unido e Espanha. Cadernos Saúde Pública, Rio de Janeiro, v. 30, n.11, p. 2263 - 2281, nov. 2014.

KEYNES, John Maynard. Teoria geral do emprego, do juro e da moeda. São Paulo: Abril Cultural, 1996. (Os Economistas). 
MAIS MÉDICOS: o que disseram Cuba e Bolsonaro sobre a saída dos cubanos do programa. BBC News Brasil, London, UK, 14 de nov. 2018. Disponível em:

https://www.bbc.com/portuguese/internacional-46210587. Acesso em: 13 mar. 2020.

MEDEIROS, Marlon Clovis. Pactos de poder e política econômica: comparações BrasilChina. Geosul, Florianópolis, SC, v. 32, n. 63, p 269-286, jan./abr. 2017.

MENICUCCI, Telma. A política de saúde no governo Lula. Saúde e Sociedade, São Paulo, SP, v. 20, n. 2, p. 522-532, jun. 2011.

OCKÉ-REIS, Carlos Otávio; FERNANDES, Artur Monteiro Prado. Descrição do gasto

tributário em saúde: 2003 a 2015. Brasília, DF, 2018. (Nota técnica Disoc. n. 48, abr.

2018). Disponível em:

https://www.ipea.gov.br/portal/images/stories/PDFs/nota_tecnica/180326_NT_48_Disoc.pdf. Acesso em: 10 dez. 2019.

SOUZA, Marina Duarte de. Saúde perdeu R\$ 20 bilhões em 2019 por causa da EC 95/2016. Brasil de Fato, São Paulo, SP, 21 fev. 2020. Disponível em:

https://referenciabibliografica.net/a/pt-br/example/index/abnt/newspaper-article. Acesso em: 8 maio 2020.

TAKAGI, Maya. A implantação do programa Fome Zero em 2003. In: SILVA, J. G. da; DEL GROSSI, M. E.; FRANÇA, C. G. de (org.). Fome zero: a experiência brasileira. Brasília, DF: MDA, 2010. p. 53-83. Disponível em: http://www.fao.org/3/a-i3023o.pdf. Acesso em: 17 fev. 2020.

TEIXEIRA, Carmen Fontes de Souza; PAIM, Jairnilson Silva. A crise mundial de 2008 e o golpe do capital na política de saúde no Brasil. Saúde em Debate, Rio de Janeiro, RJ, v. 42, p. 11-21, out. 2018. Edição especial.

VIACAVA, Francisco et al. Panorama do Programa Mais Médico (PMM) a partir do desempenho dos serviços de saúde no período 2013-2017. Boletim Informativo do

PROADESS, Rio de Janeiro, RJ, n. 6, p. 1-35, abr. 2020.

Recebido: fevereiro de 2020. Aceito: junho de 2020. 